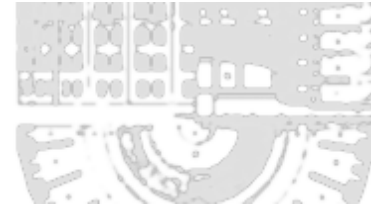 Surveillance \& Society Debate The Mythical Properties of Police Body-Worn Cameras: A Solution in the Search of a Problem
}

\section{Darren Palmer}

Deakin University, Australia. Darren.Palmer@deakin.edu.au

\section{Introduction}

Over the past few years, Australian police agencies have begun to enthusiastically introduce body-worn cameras on police personnel. These devices are now either implemented or under trial across the country. There is also an emergent 'surveillance consensus' (Hempel and Töpfer 2009) concerning their use amongst Australian police. While more detailed empirical examination of information flows that shape this surveillance consensus is warranted, this contribution to the debate seeks to draw from policing scholarship to critically explore the intersections between the rationalizations for body-worn cameras and the broader policing scholarship. More directly, body-worn cameras cannot be understood in narrow instrumental terms, but must be located within the broader literature on governing police and the law and order politics that surrounds many contemporary police and criminal justice reforms (Cox 2015; Gregg and Wilson 2015). I begin with a summary of the introduction of body-worn cameras in Australia. The article then identifies five problems body-worn cameras purportedly address and provides a brief case summary indicating how current 'privacy protections' fail to establish real limits to the collection, use, and dissemination of images from body-worn cameras.

\section{Police Body-Worn Cameras in Australia}

Victoria Police planned to introduce trials as early as June 8, 2012 (The Age 2012) and announced further trials from Christmas Eve 2013 for general duties police. The Assistant Commissioner Luke Cornelius was circumspect in the objectives:

The wearing of cameras will assist in the accurate recording of high-risk events, enable us to analyse our interactions, improve our practices and where appropriate, members may be able to use the vision captured to support prosecution (The Age 2013).

The following year (December 29, 2014) the Northern Territory Police introduced a body-worn camera trial across the Territory. In announcing an extension of the trial the justifications were far more clearly stated in law enforcement terms. In response to their own question, "Why use BWV [body-worn cameras] at all?" they answered that cameras were "an additional option for officers to gather evidence at incidents" (NT Police 2015). The 2015-16 South Australian budget (released June 18, 2015) included \$5.9 million for 1,000 body-worn cameras to be introduced over a four-year period.

Palmer, Darren. 2016. The Mythical Properties of Police Body-Worn Cameras: A Solution in the Search of a Problem. Surveillance \& Society 14(1): 138-144. 
In the lead up to the 2015 Queensland state election, the Labor opposition announced a law and order policy on January 29,2015 , committing $\$ 5$ million to body-worn cameras. Viewed as highly unlikely to win the election (though they did) the policy had no identified objective and did not address earlier concerns raised by the Police Commissioner Ian Stewart about the privacy of children and victims and the operational time lost managing these data (Cowan 2015). On September 16, 2014, the Commissioner had said:

There are issues such as police walking into a domestic violence situation, where children are involved ... [or] having the camera on when they are dealing with a sexual offence ... There is a huge cost behind this. That is about the storage of the information and it is about the classification of the information and the amount of time that the officers are going to have to spend at the end of a shift downloading it and putting into secure storage (my emphasis, Cowan 2015).

The new State Government nonetheless proceeded a year later with an announcement on September 13, 2015, for 300 body-worn cameras to enhance the policing of domestic violence, one of the key concerns expressed by the Commissioner (discussed in more detail below). Western Australia followed with an announcement on November 11, 2015, that a trial will occur in 2016 and was justified by the international evidence that body-worn cameras lead to an increase in guilty pleas and "reduced assaults on police" (Hickey 2015).

In May 2015, the New South Wales government announced \$4 million for body-worn cameras following a 2013-14 trial. On September 17, 2015, the New South Wales Police Commissioner Andrew Scipione announced the initial roll out of body-worn cameras for NSW police in one region, as well as use by specialist squads such as Riot Police. The Commissioner made the perceived benefits in implementing this technology clear: "When people know the incident is being recorded, they [both police and the public] behave differently" (Kidd 2015). He then proceeded to claim the additional benefit was to assist with prosecution and convictions, indicating that the main emphasis was on improvements in gathering evidence (Douglas and Goodmark 2015). The Acting Assistant Commissioner hinted at another purpose as a "digital notebook" - if "they're going to record particulars in their notebook, then they should activate their camera" (Kidd 2015).

With the exception of Queensland, no police agencies announcing the trials or introduction of body-worn cameras have discussed the potential illegality of the use of listening devices without a warrant, an offence under various privacy and surveillance devices legislation across the country unless there is consent (De Zwart, Humphreys, and Van Dissel 2014). Police agencies generally seem to be relying on common law or broad police statutory powers (see College of Policing 2014) and law enforcement exceptions to privacy and surveillance or listening devices legislation (e.g. Surveillance Devices Act 1999 Vic. s. $3(2)$ (c) allowing police to record if one party to the conversation consents, they are acting in the course of their duty, and the officer "reasonably believes that it is necessary"). The Queensland government determined it must amend the Police Powers and Responsibilities Act 2000 so that police would not be in potential breach of the provisions of the Invasion of Privacy Act 1971. The latter makes it an offence for anyone to use a 'listening device' to overhear, monitor, record, or listen to a private conversation (s. 43) unless they are a party to the conversation (s. 43(2)(a)) or are a police officer authorized by a warrant to use the listening device (s. 43(2)(d)). The amendment allows police to use the body-worn camera as a listening device under an exception to the Invasion of Privacy Act 1971, but does not otherwise change requirements concerning covert surveillance devices. In late 2014, NSW amended the Surveillance Devices Act 2007 (Surveillance Devices Amendment (Police Body-Worn Video) Act 2014) and, like Queensland, put forward domestic violence as the justification for body-worn camera introduction, even though they can be used in any policing context. The only restrictions are that the use must be overt, or people being recorded must be informed of the recording (s. 50A(1)). However, any "inadvertent or 
unexpected" or "incidental" recording is not an offence (s. 50A(3)). Other jurisdictions will most likely have to introduce similar legal provisions once body-worn cameras are implemented after completing trials.

All police agencies justify the use of body-worn cameras as enhancing crime prevention and law enforcement outcomes (less offending, increased prosecution and guilty pleas) and, secondarily, because of the benefits of this technology as enhancing police accountability. However this begs three questions: what are the problems with efficiency that body-worn cameras are positioned to address; what evidence is being used to claim these perceived benefits; and, are there any potential 'costs' to be considered?

To answer these questions we need to place this latest technological solution to policing within the broader policing context. Police work involves far more than crime fighting and crime prevention, yet even in these areas police responses might be non-existent (the under-policing problem), might be too little too late ('calls for service' response times targets), or might be quite different from the wishes of the person or group seeking a police response. To acknowledge this is to understand the importance of factors beyond the situational contingencies of street policing and to recognize broader structures governing police work and police practices (historical, organizational, legal, and cultural (see Manning 2010: 31-7; Chan 1997)). This means body-worn cameras cannot be understood in narrow instrumental terms, but must be located within the broader literature on governing police and law and order politics.

\section{Five Policing Problems}

So what then is being problematized in these discussions of the need for body-worn cameras? The normal discourse is usually a combination of enhanced police accountability; decreased use of force; decreased public misbehavior, including assaults against police; better outcomes in prosecutions and convictions; and, finally, decreased complaints against police, particularly false complaints. However, the policing research literature has addressed all these issues in some detail and this allows us to assess how body-worn cameras might enhance both the governing of and governing by police.

\section{Decreasing Complaints against Police}

The last issue of 'false complaints' is, to put it mildly, a key myth identified in the police accountability literature. In fact, the main problem in this area is developing a complaints system that is easy to access, robust in its investigations, independent, and gains public trust that there will not be any negative outcomes for making a complaint against police (Lerman and Weaver 2014: 67). But rather than reassure potential complaints, police agencies ensure they highlight the dangers of making a false complaint. For instance, the Victoria Police complaint page displayed this message in red:

\section{$* * * *$ WARNING**** Making a false complaint or creating a false belief may be an offence under the Crimes Act 1958 or the Independent Broad-based Anti-corruption Act 2011.}

Queensland Police's homepage has a section heading and text indicating that a false complaint is a criminal offence (under the Police Services Administration Act 1990) and the same for the Tasmania Police (Police Offences Act 1935). New South Wales' homepage adds that penalties are up to 12 months imprisonment under the Police Act 1990, or up to seven years under the Crimes Act 1900 if falsely accusing police of a crime.

Beyond addressing the central features of a complaints system outlined above, the key issue identified in the literature is how to overcome the 'dark figure' of police deviance-police malpractice that is not recorded. Body-worn cameras might assist in addressing this problem and encourage more complaints if complainants are permitted to access recorded data, but this rests upon so many assumptions, such as 
having a robust records and storage system, policies relating to when an officer may turn the body-worn camera on or off, accessibility of request systems and freedom of information, and so on. However, the policing literature is replete with the police failings on data management (see Commissioner for Law Enforcement Data Security 2010) and the failures to address the "backstage" of police work (Chan 2000), notwithstanding "policing's new visibility" (Goldsmith 2010).

\section{Enhancing Police Accountability}

Will body-worn cameras enhance police accountability generally? Police-public interaction on the streets is but one part of the police accountability literature. The example of Queensland is instructive about how body-worn cameras can be promoted to enhance accountability, yet are positioned politically in ways that detract from accountability.

As indicated above, the Queensland Premier introduced body-worn cameras as a means of enhancing police responses to domestic violence (Douglas and Goodmark 2015). On September 13, 2015, the Premier announced a "fast track" roll out of 300 body-worn cameras to the Gold Coast area in response to two murders and one machete attack on women in the preceding week (Palaszczuk 2015). Introducing body-worn cameras was put forward as evidence of implementing recommendations of the February, 2015, Not Now, Not Ever report into family violence (Special Taskforce on Domestic and Family Violence 2015). The problem was, body-worn cameras were never mentioned in the report, though the issue of police accountability was:

Unfortunately, the Taskforce heard many stories about the shortcomings of police responses. Many of these shortcomings stem from processes and procedures that inhibit police responses, but many also come from a culture in some areas that does not give sufficient weight to what was seen as "just a domestic" (Special Taskforce on Domestic and Family Violence 2015: 14).

The Taskforce was recommending greater individual and organizational accountability among police forces to address the under-policing of family violence. Police culture and procedures were the identified problems and body-worn cameras were never mentioned as part of the solution.

\section{Decreasing Police Use of Force}

The need to reduce police use of force has garnered the most support for body-worn cameras and particularly so in the US. After several high profile incidents of police killing US citizens, President Obama rushed to request "Congress to buy 50,000 police cameras" (Sutherland and Ariel 2014). However, one technological intervention is unlikely to effectively address the inappropriate use of force by police. Fundamental and holistic changes to training, supervision, powers, and cultures are necessary (Manning 2015). Put simply, there needs to be instilled within any police agency a culture of safety first and minimum use of force. To achieve this there needs to be strong organizational leadership and regular associated training regimes, matters addressed in detail through a series of inquiries in the 1990s (Palmer 1998).

\section{Decreasing Public Offending and Assaults against Police}

Will body-worn cameras decrease public misbehavior and assaults on police? At a general level, CCTV has shown video recording citizens does not of itself produce a decrease in misbehavior. However, bodyworn camera video recording has a greater immediacy and intimacy compared to CCTV (Sutherland and Barak 2014) and might have a positive impact (Ariel, Farrar, and Sutherland 2015). Nonetheless, a large part of this violence and anti-social behavior happens when and where people are likely to be under the influence of alcohol and/or drugs with depleted cognitive functioning. Key preventative measures that have proven to work involve restrictions to access to alcohol (see Graham and Homel 2012), which are largely resisted by the alcohol industry. 
Assaults on police clearly do happen but the broader police accountability literature has identified police use of the 'trifecta' as a key problem: charges of 'abusive language,' 'resist arrest,' and 'assault police,' which are then used to thwart any potential complaint, and for charge bargaining and plea negotiations. Understanding such police uses of law as a resource (Dixon 1997) shapes police data on public offending and assaults on police.

\section{Improving Prosecution Outcomes and Convictions}

Finally, there are claimed benefits of enhancing prosecutions and convictions. This depends on the types of offences involved. Public order offences have extremely high levels of prosecutorial success, no doubt due to the filtering that goes on before there is even the possibility of a contested trial. It is only as we increase the seriousness of offence and associated higher penalties that the idea of contesting charges becomes more possible and evidence is more likely to be tested. Body-worn cameras will have a limited impact on the prevention of family violence, sexual assaults, serious non-sexual assaults, and deaths - the police generally are not there to video record the act. The main claim is that allowing contemporaneous recordings to be used as evidence without the need for the victim to appear in court to give evidence in chief will enhance convictions. This remains to be seen. However, as identified above with regard to family violence, the Queensland justification, police culture and accountability was the identified problem, not the absence of video recordings. There are many other ways to improve prevention, prosecution, and conviction rates in family violence cases, particularly by enhancing support services that are always underfunded and secondary (at best) to law enforcement resourcing.

\section{The Limits to Privacy}

Are privacy protections one means of limiting the already failing body-worn cameras? In general terms Australian privacy law and jurisprudence is "woefully underdeveloped" (de Zwart, Humphreys, and Dissel 2014) and even more so in the specific area concerning police data collection. However, there has been a recent case in Victoria challenging police recording of public events and retaining recorded data (Caripis 2012). The case involved police taking photos and videos of people protesting against coal mines. The 2010 protest was peaceful and no crimes were committed (Caripis 2012: 3). Caripis participated in the protest and was photographed and videoed and wanted the resulting images destroyed. Caripis complained to the Privacy Commissioner who in turn referred the complaint to the Victorian Civil and Administrative Tribunal (VCAT, as required under the Information Privacy Act 2006, s. 29). The VCAT used outdated cases from England and Europe and, despite the Victorian Charter of Human Rights and Responsibilties Act 2006 principle that a person has a right to privacy and protection of reputation (s. 13), determined the operating procedures for the retention and destruction of records under the Public Records Act 1973 overrode privacy. In other words, policing and law enforcement "requirements" buttressed by limitations on the destruction of state records thwarted the Charter and information privacy principles. As Goldenfein's (2013) review of the case suggests, this approach might be challenged in the future and the use of data protection regimes might prove more beneficial to limiting law enforcement's negation of information privacy protections by using data protection principles. However, the current Victorian legislation (Privacy and Data Protection Act 2014) continues to provide exemptions to Information Privacy Principles where police believe the collection of information and the use and disclosure of information is necessary on reasonable grounds for law enforcement and community policing (s. 15). There is similar legislation across the country whereby policing 'needs' trump privacy and data protection principles.

\section{Conclusion}

As Ben Brucato (2015) has recently suggested in this journal, it is no accident that body-worn cameras and other police recording devices have emerged at a time of increasing sousveillance of police. However, 
as indicated regarding Queensland some senior police have expressed serious reservations about bodyworn camera use only to be overridden by law-and-order politics. Body-worn cameras need to be considered within the decades of policing scholarship and inquiries addressing police accountability in the broader sense. As Peter Manning (2015) rhetorically asks, "Will the widespread use of body cameras improve police accountability? No," at least not without significant broader changes to police accountability regimes and practices.

\section{Cases}

Caripis v Victoria Police (Health and Safety) [VCAT] 1472.

\section{References}

Ariel, Barak, William A. Farrar, and Alex Sutherland. 2015. "The Effect of Police Body-Worn Cameras on use of Force and Citizens Complaints against Police: A Randomized Controlled Trial.” Journal of Quantitative Criminology 31(1):50935.

Brucato, Ben. 2015. "Policing Made Visible: Mobile Technologies and the Importance of Point of View." Surveillance \& Society 13(3/4):455-73.

Chan, Janet. 2000. "Backstage Punishment: Police Violence, Occupational Culture, and Criminal." In Violence and Police Culture, edited by Tony Coady, Steve James, Seumas Miller, and Michael O'Keefe, 85-108. Carlton: Melbourne University Press.

Chan, Janet. 1997. Changing Police Culture: Policing in a Multicultural Society. Melbourne: Cambridge University Press.

Cox, Kaleb. 2015. "The Case for (and against) Police Body-Worn Cameras." Police Accountability Project, May 15. Accessed February 18, 2016. http://www.policeaccountability.org.au/commentary/the-case-for-and-against-police-body-worncameras/.

College of Policing. 2014. Body-Worn Video. Coventry: College of Policing.

Commissioner for Law Enforcement Data Security. 2010. Consolidated Implementation Reviews 2010. Melbourne: Commissioner for Law Enforcement Data Security. Accessed February $18,2016$. http://www.chiefexaminer.vic.gov.au/content.asp?a=CLEDSBridgingPage\&Media ID=81411.

Cowan, Paris. 2015. "Qld Labor commits to body-cameras for police.” Itnews. 30 January. Accessed February $18,2016$. http://www.itnews.com.au/news/qld-police-not-convinced-by-body-worn-cameras-392153.

De Zwart, Melissa, Sal Humphreys, and Beatrix Van Dissel. 2014. "Surveillance, Big Data and Democracy: Lessons for Australia from the US and UK." University of New South Wales Law Journal 37(2):713-747.

Dixon, David. 1997. Law in Policing: Legal Regulation and Police. Oxford: Clarendon Press.

Douglas, Heather and Leigh Goodmark. 2015. "Beware the unintended consequences of body-worn cameras." The Conversation. September 29. Accessed February 19, 2016. http://theconversation.com/beware-the-unintended-consequences-of-policeworn-body-cameras-47882.

Goldenfein, Jake. 2013. "Police Photography and Privacy: Identity, Stigma and Reasonable Expectation." University of New South Wales Law Journal. 36(1):256-70.

Goldsmith, Andrew. 2010. "Policing's New Visibility." British Journal of Criminology 50:914-34.

Graham, Kathryn and Ross Homel. 2012. Raising the bar: Preventing aggression in and around bars, pubs and clubs. London: Routledge.

Gregg, Melissa and Jason Wilson. 2015. "The Myth of Neutral Technology.” The Atlantic 16 January. Accessed February 18, 2016. http://www.theatlantic.com/technology/print/2015/01/the-myth-of-neutral-technology/384330/.

Hempel, Leon and Eric Töpfer. 2009. "The Surveillance Consensus: Reviewing the Politics of CCTV in Three European Countries." European Journal of Criminology 6(2):157-77.

Hickey, P. 2015. "WA police to trial body-worn video cameras." Perth Now, 11 November 2015. Accessed February $15,2016$. http://www.perthnow.com.au/news/western-australia/wa-police-to-trial-bodyworn-video-cameras/newsstory/875682ab265b09b3b317ebf6c6eac636\#load-story-comments.

Kidd, Jessica. 2015. "New South Wales police issued body cameras to record actions, gain video evidence." ABC News online. Accessed February 16, 2016. http://www.abc.net.au/news/2015-09-17/nsw-police-to-wear-body-cameras/6783862.

Lerman, Amy E. and Vesla M Weaver. 2014. Arresting Citizenship: The Democratic Consequences of American Crime Control. Chicago: University of Chicago Press.

Manning, Peter K. 2015. "Will the widespread use of body cameras improve police accountability? No." Americas Quarterly, Technology in Latin America. Spring 2015. Accessed February 14, 2016. http://www.americasquarterly.org/content/nonew-technologies-wont-change-behavior.

Manning, Peter K. 2010. Democratic Policing in a Changing World. Boulder, CO: Paradigm Publishers.

NT Police. 2015. Body worn video trial. Accessed February 16, 2016. http://www.pfes.nt.gov.au/Police/Community-safety/Bodyworn-video-trial.aspx.

Palaszczuk, Anna. 2015. Media Statement. Accessed $\quad$ February $18, \quad 2016$. http://statements.qld.gov.au/Statement/2015/9/13/palaszczuk-government-moves-to-tackle-domestic-violence. 
Palmer, Darren. 1998. "Confronting police culture or 'the force is still with you?' Making sense of contemporary policing in Australia.” International Journal of Police Science and Management 1(4):333-46.

Special Taskforce on Domestic and Family Violence. 2015. Not Now, Not Ever: Putting an End to Domestic and Family Violence in Queensland. (n.d.) $28 \quad$ February 2015. Accessed February $16,2016$. https://www.qld.gov.au/community/documents/getting-support-health-social-issue/dfv-report-vol-one.pdf.

Sutherland, Alex and Barak Ariel. 2014. "The jury's still out." The Conversation (US), December 23. Accessed February 19, 2016. https://theconversation.com/cameras-on-cops-the-jurys-still-out-35644.

The Age Editorial. 2012. "Police union doth protest too much on cam trial." June 11. Accessed February $18,2016$. http://www.theage.com.au/federal-politics/editorial/police-union-doth-protest-too-much-on-cam-trial-2012061020498.html.

The Age. 2013. "Victoria Police to trial body cameras." The Age Online, December 24. Accessed February $18,2016$. http://www.theage.com.au/victoria/victoria-police-to-trial-body-cameras-20131223-2zv52.html. 